\title{
sciendo
}

\section{Voluntary employee attrition. Descriptive and predictive analysis}

\author{
Raluca-Dana CĂPLESCU \\ The Bucharest University of Economic Studies \\ Raluca.Caplescu@csie.ase.ro \\ Miruna ILIE \\ The Bucharest University of Economic Studies \\ Miruna.Ilie@gmail.com \\ Vasile Alecsandru STRAT \\ The Bucharest University of Economic Studies \\ vasile.strat@bbs.ase.ro
}

\begin{abstract}
Voluntary attrition represents the percent of employees voluntarily leaving a company. Counteracting this phenomenon with hiring new employees has a great negative impact on the company for several reasons. Firstly, it hinders timely delivery of current projects and, consequently, damages reputation and diminishes client portfolio. Secondly, it increases costs by generating the need for many recruitment specialists. Thus, adapting the HR strategy is essential, especially as increasingly more Millennials enter the labor market. The present paper aims at presenting options for studying voluntary attrition and the situations when they can be used. We indicate both descriptive methods (turnover and retention rates, cohort analysis), in order to present tools that any HR manager can easily employ, and predictive methods (logistic regression, survival analysis), which are more accurate and provide more actionable insight towards minimizing attrition, but require data and skills. The results are presented comparatively, highlighting the advantages and disadvantages of each category. Most literature focuses on a single method, thus the main contribution of this article is that it compares several methods, allowing for an informed decision of the HR specialist, depending on the company's resources, personnel qualification and specific context.
\end{abstract}

Keywords: voluntary attrition analysis, employee attrition, human resources, predictive methods, descriptive methods, method comparison.

\section{Introduction}

The phenomenon of employees leaving the company is referred to as attrition, churn rate or turnover. Depending on the reason why employees leave, attrition can be natural (retirement), involuntary or voluntary (McQuerrey, 2019). Involuntary attrition is due to any reasons a company might have to reduce or replace personnel, while voluntary attrition is caused by the employees' own decision to leave a company.

In general, a high turnover implies elevated costs for a company and, while employers have high control on natural (can prepare beforehand) and involuntary attrition, voluntary attrition may generate significant loss. The normal activity of any company requires a minimum personnel size. Having to deal with a big churn rate impacts the company manifold, 
from resource allocation to image capital. Shifting focus from production to recruitment triggers reputational and client loss, also decreasing profitability. Frequent acclimatization and training of new employees hinders project delivery and requires a relatively large Human Resources (HR) department, which also incurs additional costs.

One factor that greatly impacts voluntary attrition is the employee's generation, as it reflects their core views, values and lifestyles. Consequently, considering the characteristics of both present and future generations on the labor market is crucial. For companies to adapt their HR strategies, they need to understand the people who form the human resource. The literature distinguishes between three generations: Baby Boomers, Generation X and the Millennials (Smith \& Nichols, 2015). It is worth mentioning that the following division and the characteristics of the three generations vary between countries and regions. For the purpose of this paper, we will use the US-based description.

The Baby Boomers are born during the peak of birth rates following World War II (1943-1960) and were brought up in thriving economies. Technological advances did not mark their formative years; thus, they are neither dependent on, nor proficient in using them (Smola \& Sutton, 2002). In contrast, Generation X members (1961- 1979) are less numerous than and their childhood was marked by recessions, two-full-time-working parents, divorce and increasing crime rates (Cahill \& Sedrak, 2012). The generation that is currently entering the workforce is called Millennials (1980-2000). Their early youth was greatly impacted by computers and the digital age and they exhibit greater openness towards non-traditional family and values (Andert, 2011).

As more Millennials enter the labor market, several poignant differences between the them and the older generations have been highlighted. Companies' failure to adapt their HR strategies will lead to increasing costs and intense intercompany employee flows. Research indicates that the newer generations' set of values differs greatly from the previous' ones. what stands out most in the Millennials is the shift of preference from well-paid jobs to meaningful work (Smith \& Nichols, 2015). They seek jobs allowing them to enjoy their work, use their creativity, innovate and create positive social impact, and are attracted to flexible schedules, transparent, authentic and egalitarian workplaces. This provides a starting point towards adapting the organizational culture to attract and maintain younger employees.

Millennials express their opinion more frequently, make greater demands and place more value on the work/life balance (Deal, Altman, \& Rogelberg, 2010; Levenson, 2010; Meyers \& Sadaghiani, 2010). Moreover, they rank higher on assertiveness, self-confidence and self-esteem, compared to the previous generations at the same age (Smith \& Nichols, 2015). Millennials are achievement-focused, constantly seek new opportunities to learn and grow, are more willing to work extra and contribute to the success of their organization. They are open to working in teams to a greater extent and generally more tolerant compared to the older generations (Andert, 2011; Smith \& Nichols, 2015).

Companies do not need to base their strategies solely on research. They can collect and analyze their own data. It may be biased towards a certain profile, but unlike in academics, this is not necessarily problematic. Based on such information the analytics and HR teams may conclude that the company should continue the search for the current employee profile, change parts of it or replace it entirely. For business practitioners, the most important result is the one that refers to their company, while academics focus rather on generalizations.

As increasingly more data are collected through information systems, analytics 
emerges as an alternative to more human intensive work. HR can also benefit from analytics, provided it is used and implemented reasonably (Rasmussen \& Ulrich, 2015). While traditional indicators, such as turnover and retention rates, are in the toolbox of any HR specialist, more complex analysis can reveal further insight. Descriptive methods, combined with qualitative analysis, are efficient and effective methods to manage the human resource of a small and/or a medium enterprise. Nonetheless, for large and multi-national companies this approach can become unmanageable.

HR Analytics (HRA) has been defined, mostly by consultants, as the use of statistical techniques for analyzing HR practices and managerial performance (Lawler III, Levenson, \& Boudreau, 2004), a useful tool in decision-making for HR (Bassi, 2011) with direct impact of people data on business (Mondare \& Carson, 2011) and monitoring of individual performance (Aral, Brynjolfsson, \& Wu, 2012).

In contrast, academics (and business practitioners) see HRA as a mere fad if adopted without analyzing its necessity or the existence of appropriate data (Rasmussen \& Ulrich, 2015; Angrave, Charlwood, Kirkpatrick, Lawrence, \& Stuart, 2016). The authors suggest starting from the business problem that needs to be solved and allocate the resources based on need, as well as making sure HRA and HR work separately towards a common goal, thus allowing HR to focus on the human side, while training HR specialists to have an analytical mindset (Rasmussen \& Ulrich, 2015).

To understand the factors a company should be focusing on to keep voluntary attrition to a minimum, several analysis methods can be employed. The present paper aims at presenting options for studying the phenomenon. The focus will be on quantitative methods, both descriptive and predictive. The results are presented comparatively, highlighting the advantages and disadvantages of each category. Most literature focuses on a single method, thus the main contribution of this article is that it presents several methods, allowing for an informed decision of the HR specialist, depending on the company's context.

The remainder of the article comprises a data and methods section, followed by the results and discussion part, which focuses on comparing descriptive and predictive methods, closing with a conclusion section.

\section{Data and methods}

The data were created by IBM Watson Analytics and contain fictional information on 1470 current and past employees, providing various information about them, from social and demographic (age, gender, marital status, education), position (department, role, travelling, hours worked, overtime, seniority in current position and in company, trainings), various aspects (distance from home, job, environment and work/life balance satisfaction), and salary and performance (rates, salary hikes, monthly income, performance rating). There is also a variable indicating whether the employee is still with the company or has left.

The data is used for demonstrating the methods and their usefulness, rather than drawing valid conclusions about strategies and approaches to be applied by HR specialists. We assumed that all employees who left the company did so voluntarily (indication on this in the data). Also, two more columns (hire year and leaving year, if applicable) were added to use the same data for all methods.

For each employee flagged with attrition we randomly generated numbers between 0 and 7 , thus generating the variable years since left. Based on this we computed the hire year, 
(2015-base year (dataset generation year)):

hire year $=2015-$ years at company -years since left

The year when the employee left the company was computed by subtracting years since left from 2015. Since the maximum number of years randomly generated was 7 , no employee left before 2008. To ensure the data makes sense, we also computed the birth year of each employee and reiterated the steps for all employees with age at hire less than 18.

The descriptive methods were computed in Excel and the predictive ones On Demand Access SAS (online platform).

\section{Descriptive methods}

The most basic attrition indicator is the turnover rate, which shows the percentage of employees who left during the analyzed period (e.g. one year) in comparison with the average personnel size for the respective period:

turnover rate $=\frac{\text { number of employees who left during the period }}{(\text { number of employees at BoP }+ \text { number of employees at EoP }) / 2} \cdot 100$

where BoP stands for Beginning-of-Period and EoP stands for End-of-Period.

Having information on several periods, the specialist can identify the trend. Values increasing significantly for longer periods should raise concerns and lead to further analysis.

In parallel, the HR specialist can track the evolution of the retention rate, which shows the percent of employees who are still working for the company compared to the beginning of the period:

$$
\text { retention rate }=\frac{\text { number of employees } \text { who did not leave during the period }}{\text { number of employees at BoP }} \cdot 100
$$

The trend in retention rate should mirror that of the turnover rate, the two indicators being complementary.

Both rates can be computed either at aggregated (company) level or at group level (division, department, seniority etc.), depending on the company's goals and interests.

Another way of looking at the data is using cohort analysis. The idea is to track the percentage of employees from each cohort that are still working for the company by the end of certain time units. To perform this analysis, we need the number of employees hired during each period (new employees) and that of employees still in the company at the EoP. Then, we compute the percentage for each employee cohort. The data must be structured as in Table 1 (see above), where $\mathrm{N}_{\mathrm{i}}$ represents the number of employees hired during year 1 and $\mathrm{n}_{\mathrm{ij}}$ represents the cumulated number of employees from a cohort who left before the $\mathrm{j}^{\mathrm{j} \text { th }}$ EoP. Finally, the percentage is obtained dividing $\mathrm{n}_{\mathrm{ij}}$ by $\mathrm{N}_{\mathrm{i}}$.

Table 1. Data structure for cohort analysis

\begin{tabular}{|l|c|c|c|c|c|}
\hline Generation & New employees & P0 & P1 & P2 & $\ldots$ \\
\hline Year 1 & $\mathrm{~N}_{1}$ & $\mathrm{n}_{10}$ & $\mathrm{n}_{11}$ & $\mathrm{n}_{12}$ & \\
\hline Year 2 & $\mathrm{N}_{2}$ & $\mathrm{n}_{20}$ & $\mathrm{n}_{21}$ & & \\
\hline Year 3 & $\mathrm{~N}_{3}$ & $\mathrm{n}_{30}$ & & & \\
\hline$\ldots$ & & & & & \\
\hline
\end{tabular}

Source: Authors' own research. 
These methods have the advantage that data is readily available, they require basic skills and no specialized software. Conversely, they provide only general information about what already happened. For explaining causes or being able to intervene, descriptive methods are unsuitable. Such insights may be obtained with the help of the next category of methods.

\section{Predictive methods}

One of the most efficient prediction methods that can be used is logistic regression. This method is based on binary classification and the outcome is the probability that an event will occur. The logistic regression does not classify employees in those who left and those who stayed, but it estimates probabilities based on which, and for a given threshold, employees can be classified as likely to leave or stay. The outcome of the model will be based on the probability that an event occurred given the predictors considered (Hosmer \& Lemeshow, 2000).

The probability that the employee left the company is determined dividing the number of employees who left by the total number of employees. The model estimates the odds that an employee left, rather than stayed, which are computed by dividing the probability that they left by the probability that they did not.

$$
\text { odds }=\frac{\text { probability employees left }}{\text { probability employees stayed }}
$$

Starting from the odds, the output contains odds ratios (OR), which are computed for each pair of baseline vs other categories of $X$ by dividing the odds for one category by the odds for the base category. This gives indication about how the likelihood to leave is influenced by the predictors.

$$
O R=\frac{\text { odds category } i}{\text { odds base category }}
$$

where $i$ represents each category of the variable $X$, except the base one. For example, we use the variable Department, with the following categories: Sales, Customer Support, IT and DevOps, and choose Sales as base. We will be able to compute three odds ratios, one for each pair of Sales and one of the other three categories. The result will indicate how many times is an employee from the other departments more likely to leave than an employee from Sales.

Given the specifics of the logistic regression, to estimate the parameters the model needs to undergo some transformations and the estimation technique used is the maximum likelihood (Hosmer \& Lemeshow, 2000). The logistic regression is implemented in most statistical software (SPSS, SAS, R, Stata etc.).

A limitation of the binary logistic regression model is that it only supports two categories. If we were interested in predicting the probability that an employee would still be employed after one year, two, three or five years since being hired, we would have to develop separate models for each hypothesis. A possible work-around are the multinomial logistic regression models (nominal and ordinal), which allow for more than two categories of the outcome variable (e.g. category 1 - leave before the end of year 1 , category 2 - leave before the end of year 2 etc.), but many categories also imply more data, require more computational power and generate a more complex output, which is harder to interpret. 
An alternative to this approach is a method called survival analysis, also known as reliability theory/analysis (engineering), duration analysis/modelling (economics) and event history analysis (sociology). The specificity of this method is that the dependent variable is a combination of time-to-event and status (event/censored). The survival and the hazard functions are two of the most important time-dependent functions estimated (Hosmer, Lemeshow, \& May, 2008).

If we define the event as voluntary attrition, this method allows the estimation of the time (measured in any time unit) the employee will spend in the company before leaving. This type of analysis is called longitudinal, because it follows the same subjects through time, and it is a more complex version of cohort analysis.

Censored information is characterized by incomplete survival time (Hosmer, Lemeshow, \& May, 2008) and the most frequent type is right censoring. Given an observation period, all employees still working for the company at the end of it are right censored. This means they have not left the company during the observed period, but we have no information on how and when they will leave in the future. Another example of right censoring is when the employee has left the company for other reasons (retirement, redundancy, restructuring, death etc.). In this case the employee did not experience the event (leaving voluntarily), but they are not with the company anymore either. This is also called right censoring because we do not know whether and when they would have left voluntarily.

The survival function for a time $t$ indicates the probability of the event not occurring (surviving) up to a given point in time. At the beginning of the study the probability of survival is generally assumed to be equal to 1 (less would mean there are employees who left at the beginning of their first day). Intuitively, this function cannot increase, since only employees who are still in the company can continue to work there at the end of time $t$. Finally, it is possible, but not necessary for the function to reach zero (last employees have left voluntarily). While no employee will work forever, some might leave for other reasons, independent of their wish (redundancy, bankruptcy, death etc.) and censored observations do not modify the survival function.

The hazard function gives the expected number of employees who will leave during a certain interval, conditional on being employed in the company up to the beginning of the respective period. The hazard function is also known as force of mortality in demography and actuarial science, other alternative names being hazard rate or force of failure. The hazard function needs to be non-negative, as it is not possible for a negative number of employees to leave the company.

The basic model supports incorporation of predictors that influence survival time. These models can be estimated using parametric, non-parametric or semiparametric methods. Parametric methods assume a known probability distribution for the underlying distribution of survival times (e.g. exponential, Weibull, Gamma, log-normal distribution) and estimation of parameters is done using maximum likelihood, modified accordingly. For the non-parametric approach, the most widely used method is Kaplan Meier, which allows for generation of descriptive statistics for survival data, as well as comparison between several groups of interest. Lastly, the best-known semiparametric method is Cox proportional hazards. Besides allowing for covariate adjustment, it does not assume a certain shape for the baseline hazard function, the relationship between the hazard function and the predictors is easy to interpret, relying on an assumption of nonlinear relationship between them, and the hazard ratio for any pair of observations is constant in time (if no time varying covariates are 
included).

Predictive methods permit analysis of the data and prediction of the most likely outcome, which, in turn allow for development of strategies that might counteract undesired results. Nevertheless, they require certain types of data, advanced analytical skills, computers with good processing power and, in some cases, expensive specialized software.

\section{Results and discussions}

This section will focus on presenting the basic way to generate the output, the results obtained and a short interpretation of the latter, followed by a short conclusion on the usefulness of the methods.

\section{Descriptive methods}

Using Excel's PivotTable we determined, for each hire year, the number of new employees, employees who left and existing number of employees at the beginning of 2008. The last value was computed by adding all employees hired up to 2007, inclusively. Subsequently, the values of each BOP are equal to those for EOP. The latter are computed as follows:

$$
E O P=B O P+\text { New empl } . \text { Left empl }
$$

Table 2. Turnover and retention rates by employment generation

\begin{tabular}{|c|c|c|c|c|c|c|}
\hline Generation & New empl. & Left employ. & BOP & EOP & Turnover rate & Retention Rate \\
\hline$(0)$ & (1) & (2) & (3) & (4) & (5) & (6) \\
\hline 2008 & 79 & 21 & 473 & 531 & $4.18 \%$ & $95.56 \%$ \\
\hline 2009 & 67 & 21 & 531 & 577 & $3.79 \%$ & $96.05 \%$ \\
\hline 2010 & 175 & 21 & 577 & 731 & $3.21 \%$ & $96.36 \%$ \\
\hline 2011 & 91 & 23 & 731 & 799 & $3.01 \%$ & $96.85 \%$ \\
\hline 2012 & 108 & 32 & 799 & 875 & $3.82 \%$ & $95.99 \%$ \\
\hline 2013 & 100 & 21 & 875 & 954 & $2.30 \%$ & $97.60 \%$ \\
\hline 2014 & 112 & 37 & 954 & 1029 & $3.73 \%$ & $96.12 \%$ \\
\hline 2015 & 28 & 61 & 1029 & 996 & $6.02 \%$ & $94.07 \%$ \\
\hline
\end{tabular}

Source: Authors' own research.

Turnover and retention rates were computed using the formula presented previously. In order to make results more easily interpretable, we formatted the values for turnover rate so that the higher the rate, the darker the color. For retention rate we reversed the formatting scale to correspond to the logic in the turnover rate. Thus, for retention rate, the lower the retention, the darker the shading. It immediately becomes obvious that both indicators were at their worst state in 2015 (black cells) and at their best state in 2013 (white cells).

Plotting the turnover rate on the primary (left) axis and the retention rate on the secondary (right) axis (Figure 1), the first thing to notice is that the two lines mirror each other, which visually confirms the intuition regarding the two indicators' complementarity. The chart also helps with easier and faster trend visualization. The company seems to have dealt effectively with voluntary attrition until 2013, but deeper analysis is necessary to understand the rapid increase in turnover since. Possible further steps are to split the analysis by department or any variable of interest. 


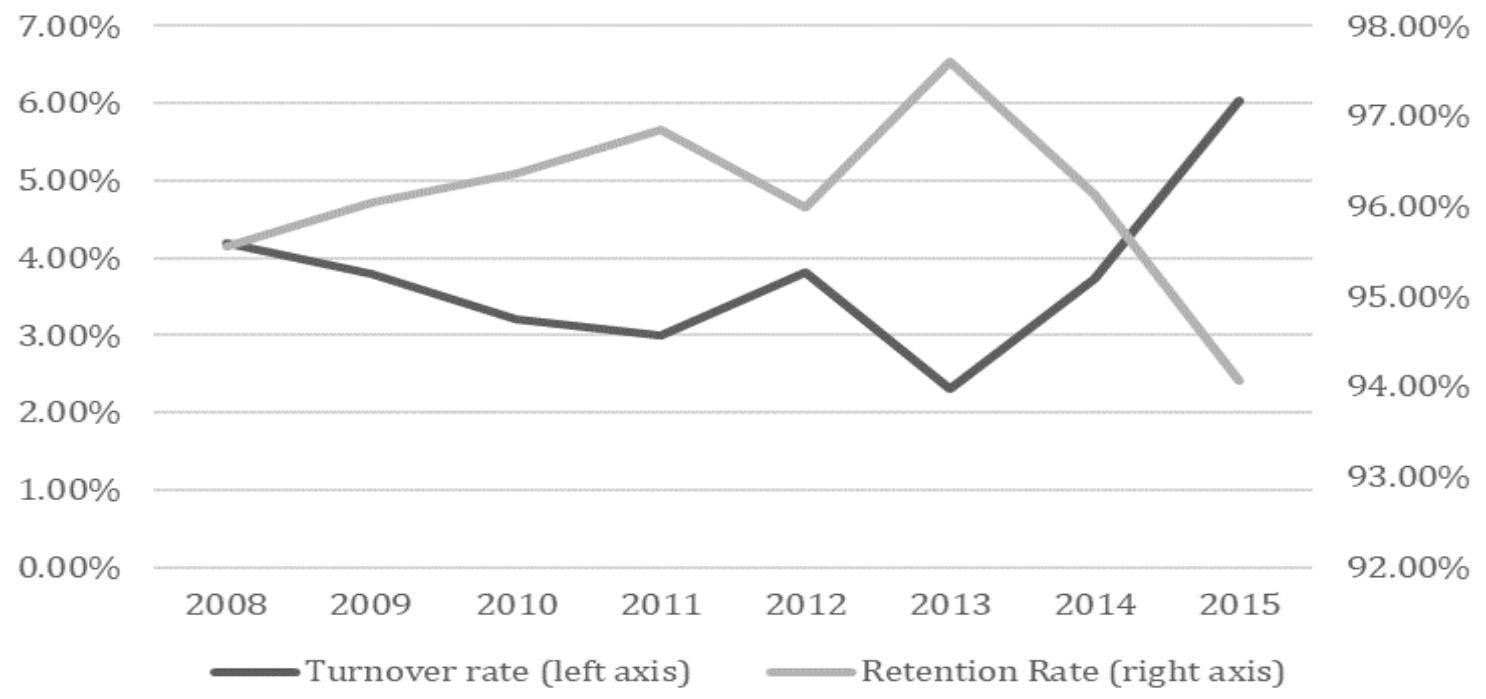

Figure 1. Turnover and retention rates

Source: Authors' own research.

Replicating the analysis at department level (Table 3), we illustrate the kind of insight that would result from deepening the analysis. We only present the period starting with 2013, as this is when the trend begins to increase. The first thing to consider is the department size, as it impacts the overall numbers. We expect the greatest impact to come from the Research\&Development (RD) department (about 60\% of all employees), followed by Sales (about 1/3) and, lastly, HR.

Table 3. Turnover and retention rates by employment generation and department Generation New empl. Left employ. BOP EOP Turnover rate Retention Rate

\begin{tabular}{|c|c|c|c|c|c|c|}
\hline$(0)$ & $(1)$ & $(2)$ & (3) & $(4)$ & $(5)$ & (6) \\
\hline \multicolumn{7}{|c|}{ Human Resources Department } \\
\hline 2013 & 6 & 2 & 49 & 53 & $3.92 \%$ & $95.92 \%$ \\
\hline 2014 & 4 & 2 & 53 & 55 & $3.70 \%$ & $96.23 \%$ \\
\hline 2015 & 0 & 4 & 55 & 51 & $7.55 \%$ & $92.73 \%$ \\
\hline \multicolumn{7}{|c|}{ Research\&Development Department } \\
\hline 2013 & 74 & 13 & 706 & 767 & $1.77 \%$ & $98.16 \%$ \\
\hline 2014 & 95 & 22 & 767 & 840 & $2.74 \%$ & $97.13 \%$ \\
\hline 2015 & 20 & 32 & 840 & 828 & $3.84 \%$ & $96.19 \%$ \\
\hline \multicolumn{7}{|c|}{ Sales Department } \\
\hline 2013 & 36 & 6 & 361 & 391 & $1.60 \%$ & $98.34 \%$ \\
\hline 2014 & 29 & 13 & 396 & 412 & $3.22 \%$ & $96.72 \%$ \\
\hline 2015 & 14 & 25 & 422 & 411 & $6.00 \%$ & $94.08 \%$ \\
\hline
\end{tabular}

The increase in turnover is obvious in all departments, but it is slowest in R\&D, while almost doubling yearly in Sales. HR also seems to have a problem with employee retention, though with some delay, but this may also be because of the high turnover in other 
departments. It has little direct impact in the company's overall turnover. Therefore, the most urgent direction of action for reversing the churn rate trend might be improving retention in the Sales department, probably followed by the HR department, which has a crucial role in the entire process, despite generating little direct impact overall.

These approaches are transversal, analyzing the entire population of employees at the same point in time. In contrast, cohort analysis has a longitudinal approach, each cohort of employees being followed through time separately.

The data in Table 4 was also obtained using Excel's PivotTable and is structured as specified in Table 1. The first column represents the year of hiring, followed by a column showing how many new employees the company hired during the respective year. The next columns contain the percentage of employees who were still in the company before completing one, two, three etc. years since being hired. They are computed by dividing the cumulative number of employees who left before the end of the respective period by the number of employees hired during the respective year. The darker the color, the worse the situation.

Table 4. Cohort analysis - overall company

\begin{tabular}{|c|c|c|c|c|c|c|c|c|c|}
\hline Generation & New empl & Y0 & Y1 & $\mathrm{Y} 2$ & Y3 & Y4 & $\mathrm{Y} 5$ & Y6 & Y7 \\
\hline 2008 & 79 & $97.5 \%$ & $88.6 \%$ & $87.3 \%$ & $86.1 \%$ & $83.5 \%$ & $83.5 \%$ & $82.3 \%$ & $75.9 \%$ \\
\hline 2009 & 67 & $98.5 \%$ & $91.0 \%$ & $88.1 \%$ & $79.1 \%$ & $76.1 \%$ & $70.1 \%$ & $65.7 \%$ & \\
\hline 2010 & 175 & $99.4 \%^{\top}$ & $96.0 \%^{\top}$ & $93.7 \%$ & $93.1 \%{ }^{\prime}$ & $92.0 \%$ & $89.7 \%$ & & \\
\hline 2011 & 91 & $97.8 \%^{\top}$ & $92.3 \%^{\top}$ & $85.7 \%$ & $83.5 \%$ & $80.2 \%$ & & & \\
\hline 2012 & 108 & $98.1 \%^{\top}$ & $97.2 \%^{\prime}$ & $90.7 \%$ & $88.0 \%$ & & & & \\
\hline 2013 & 100 & $98.0 \%$ & $88.0 \%$ & $84.0 \%$ & & & & & \\
\hline 2014 & 112 & $100.0 \%$ & $85.7 \%$ & & & & & & \\
\hline 2015 & 28 & $78.6 \%$ & & & & & & & \\
\hline
\end{tabular}

Source: Authors' own research.

The 2009 employee cohort stands out for having lost almost half of its members before the reporting time, thus employees hired then are likely to leave the company sooner than their counterparts. Also, the 2015 cohort stands out for having the lowest retention rate during the first year. Given the simulated nature of the data, this may be due to chance, but in a real setting, this could indicate that the hiring process was less strict, possibly due to a stringent need to replace former employees.

Detailing the analysis at department level (Table 5), we can confirm the previous finding that addressing retention of Sales employees would greatly impact overall attrition, as these employees are leaving to a greater extent from most cohorts and for most seniority years. While it is true that the sales department of a company generally faces higher turnover than other departments, these employees are also a client's first contact with the company. Motivating these employees brings great business value. The R\&D department also shows unfavorable evolutions (newer employees tend to leave earlier than older ones, as seen in the decreasing percentage of those reaching a certain seniority period. 
Table 5. Cohort analysis by department

\begin{tabular}{|c|c|c|c|c|c|c|c|c|c|}
\hline Generation & New empl & Yo & Y1 & Y2 & Y3 & Y4 & Y5 & Y6 & Y7 \\
\hline \multicolumn{10}{|c|}{ HR Department } \\
\hline 2008 & 5 & $100.0 \%$ & $100.0 \%$ & $100.0 \%$ & $100.0 \%$ & $80.0 \%$ & $80.0 \%$ & $80.0 \%$ & $60.0 \%$ \\
\hline 2009 & 6 & $100.0 \%$ & $83.3 \%$ & $66.7 \%$ & $66.7 \%$ & $66.7 \%$ & $50.0 \%$ & $50.0 \%$ & \\
\hline 2010 & 11 & $100.0 \%$ & $100.0 \%$ & $100.0 \%$ & $90.9 \%$ & $90.9 \%$ & $90.9 \%$ & & \\
\hline 2011 & 4 & $100.0 \%$ & $100.0 \%$ & $75.0 \%$ & $75.0 \%$ & $75.0 \%$ & & & \\
\hline 2012 & 6 & $100.0 \%$ & $100.0 \%$ & $100.0 \%$ & $100.0 \%$ & & & & \\
\hline 2013 & 6 & $100.0 \%$ & $100.0 \%$ & $100.0 \%$ & & & & & \\
\hline 2014 & 4 & $100.0 \%$ & $25.0 \%$ & & & & & & \\
\hline 2015 & 0 & & & & & & & & \\
\hline \multicolumn{10}{|c|}{ R\&D Department } \\
\hline 2008 & 57 & $100.0 \%$ & $93.0 \%$ & $93.0 \%$ & $91.2 \%$ & $91.2 \%$ & $91.2 \%$ & $91.2 \%$ & $86.0 \%$ \\
\hline 2009 & 57 & $98.2 \%$ & $93.0 \%$ & $93.0 \%$ & $89.5 \%$ & $89.5 \%$ & $86.0 \%$ & $84.2 \%$ & \\
\hline 2010 & 127 & $99.2 \%$ & $96.9 \%$ & $94.5 \%$ & $94.5 \%$ & $92.9 \%$ & $92.1 \%$ & & \\
\hline 2011 & 80 & $97.5 \%$ & $93.8 \%$ & $90.0 \%$ & $88.8 \%$ & $85.0 \%$ & & & \\
\hline 2012 & 83 & $98.8 \%$ & $97.6 \%$ & $94.0 \%$ & $92.8 \%$ & & & & \\
\hline 2013 & 74 & $97.3 \%$ & $89.2 \%$ & $86.5 \%$ & & & & & \\
\hline 2014 & 95 & $100.0 \%$ & $88.4 \%$ & & & & & & \\
\hline 2015 & 20 & $90.0 \%$ & & & & & & & \\
\hline \multicolumn{10}{|c|}{ Sales Department } \\
\hline 2008 & 36 & $94.4 \%$ & $86.1 \%$ & $83.3 \%$ & $83.3 \%$ & $80.6 \%$ & $80.6 \%$ & $77.8 \%$ & $75.0^{\prime}$ \\
\hline 2009 & 27 & $100.0 \%$ & $96.3 \%$ & $92.6 \%$ & $77.8 \%$ & $70.4 \%$ & $66.7 \%$ & $59.3 \%$ & \\
\hline 2010 & 55 & $100.0 \%$ & $94.5 \%$ & $92.7 \%$ & $92.7 \%$ & $92.7 \%$ & $87.3 \%$ & & \\
\hline 2011 & 25 & $100.0 \%$ & $92.0 \%$ & $84.0 \%$ & $80.0 \%$ & $80.0 \%$ & & & \\
\hline 2012 & 32 & $96.9 \%$ & $96.9 \%$ & $84.4 \%$ & $78.1 \%$ & & & & \\
\hline 2013 & 36 & $100.0 \%$ & $88.9 \%$ & $83.3 \%$ & & & & & \\
\hline 2014 & 29 & $100.0 \%$ & $93.1 \%$ & & & & & & \\
\hline 2015 & 14 & $71.4 \%$ & & & & & & & \\
\hline
\end{tabular}

Source: Authors' own research.

The main advantages of descriptive methods are that all companies collect the necessary information, it is easily accessible, does not require many resources and any HR specialist can compute and interpret them, as the skills required are basic and no specialized software is needed.

Conversely, the results are very descriptive and, while allowing for deepening the analysis up to a certain level, they only provide a general picture of the past and do not permit cause identification. This is not necessarily problematic, if complemented with qualitative analysis. After identifying the group where the problem is most stringent, the HR department may conduct interviews or focus-groups to identify the cause and gather suggestions for improvement. Smaller enterprises, where direct interaction with employees is possible, may benefit greatly from such an approach, as it is very resource efficient.

If directly discussing with employees is not feasible because it would be too time consuming, turning to analytics can be an efficient alternative. Performing such analyses requires specialized software, analytic skills and sometimes important computational power.

\section{Predictive methods}

Binary logistic regression is very useful in estimating the likelihood that an employee would 
leave, based on their characteristics. The results may be used to generate profiles for employees who are most likely to leave/stay.

The basic output of this method contains several important elements: internal coding of the outcome and independent categorical variables, information regarding model goodness-of-fit and parameter estimates (Figure 2).

\begin{tabular}{|r|l|r|}
\hline \multicolumn{3}{|c|}{ Response Profile } \\
\hline $\begin{array}{r}\text { Ordered } \\
\text { Value }\end{array}$ & left1 & $\begin{array}{r}\text { Total } \\
\text { Frequency }\end{array}$ \\
\hline 1 & 0 & 1308 \\
\hline 2 & 1 & 162 \\
\hline
\end{tabular}

\begin{tabular}{|c|c|c|c|c|c|}
\hline \multicolumn{6}{|c|}{ Class Level Information } \\
\hline \multirow{2}{*}{$\begin{array}{l}\text { Class } \\
\text { gen }\end{array}$} & \multirow{2}{*}{$\begin{array}{l}\text { Value } \\
0\end{array}$} & \multicolumn{4}{|c|}{ Design Variables } \\
\hline & & 1 & & & \\
\hline & 1 & 0 & & & \\
\hline \multirow[t]{2}{*}{ ovt } & 0 & 1 & & & \\
\hline & 1 & 0 & & & \\
\hline \multirow[t]{3}{*}{ marital } & 0 & 1 & 0 & & \\
\hline & 1 & 0 & 1 & & \\
\hline & 2 & 0 & 0 & & \\
\hline \multirow[t]{3}{*}{ travel } & 0 & 1 & 0 & & \\
\hline & 1 & 0 & 1 & & \\
\hline & 2 & 0 & 0 & & \\
\hline \multirow[t]{3}{*}{ dept } & 0 & 1 & 0 & & \\
\hline & 1 & 0 & 1 & & \\
\hline & 2 & 0 & 0 & & \\
\hline \multirow[t]{4}{*}{ Joblnvolvement } & 1 & 1 & 0 & 0 & \\
\hline & 2 & 0 & 1 & 0 & \\
\hline & 3 & 0 & 0 & 1 & \\
\hline & 4 & 0 & 0 & 0 & \\
\hline \multirow[t]{5}{*}{ JobLevel } & 1 & 1 & 0 & 0 & 0 \\
\hline & 2 & 0 & 1 & 0 & 0 \\
\hline & 3 & 0 & 0 & 1 & 0 \\
\hline & 4 & 0 & 0 & 0 & 1 \\
\hline & 5 & 0 & 0 & 0 & 0 \\
\hline \multirow[t]{4}{*}{ JobSatisfaction } & 1 & 1 & 0 & 0 & \\
\hline & 2 & 0 & 1 & 0 & \\
\hline & 3 & 0 & 0 & 1 & \\
\hline & 4 & 0 & 0 & 0 & \\
\hline
\end{tabular}

Model Fit Statistics

\begin{tabular}{|l|r|r|}
\hline \multicolumn{3}{|c|}{ Model Fit Statistics } \\
\hline Criterion & Intercept Only & Intercept and Covariates \\
\hline AIC & 1022.009 & 592.577 \\
\hline SC & 1027.302 & 709.023 \\
\hline-2 Log L & 1020.009 & 548.577 \\
\hline
\end{tabular}

\begin{tabular}{|l|r|r|r|}
\hline \multicolumn{4}{|c|}{ Type 3 Analysis of Effects } \\
\hline Effect & DF & $\begin{array}{r}\text { Wald } \\
\text { Chi-Square }\end{array}$ & Pr $>$ ChiSq \\
\hline ovt & 1 & 68.7767 & $<.0001$ \\
\hline marital & 2 & 28.1408 & $<.0001$ \\
\hline travel & 2 & 20.8028 & $<.0001$ \\
\hline dept & 2 & 23.3305 & $<.0001$ \\
\hline gen & 1 & 4.5884 & 0.0322 \\
\hline YearsAtCompany & 1 & 80.4377 & $<.0001$ \\
\hline DistanceFromHome & 1 & 20.8457 & $<.0001$ \\
\hline NumCompaniesWorked & 1 & 8.0989 & 0.0044 \\
\hline Joblnvolvement & 3 & 18.9783 & 0.0003 \\
\hline JobLevel & 4 & 47.5261 & $<.0001$ \\
\hline JobSatisfaction & 3 & 28.4048 & $<.0001$ \\
\hline
\end{tabular}

\begin{tabular}{|c|c|c|c|c|c|c|}
\hline \multicolumn{7}{|c|}{ Analysis of Maximum Likelihood Estimates } \\
\hline Parameter & & DF & Estimate & $\begin{array}{l}\text { Standard } \\
\text { Error }\end{array}$ & $\begin{array}{r}\text { Wald } \\
\text { Chi-Square }\end{array}$ & $\mathrm{Pr}>\mathrm{ChiSq}$ \\
\hline Intercept & & 1 & 3.1310 & 1.3588 & 5.3251 & 0.0210 \\
\hline ovt & 0 & 1 & 1.8482 & 0.2385 & 68.7767 & $<.0001$ \\
\hline marital & 0 & 1 & -1.2447 & 0.3172 & 15.3937 & $<.0001$ \\
\hline marital & 1 & 1 & -0.0448 & 0.3208 & 0.0183 & 0.8895 \\
\hline travel & 0 & 1 & 1.7788 & 0.4883 & 12.7421 & 0.0004 \\
\hline travel & 1 & 1 & 1.1135 & 0.2708 & 16.8093 & $<.0001$ \\
\hline dept & 0 & 1 & 1.1882 & 0.2874 & 20.0742 & $<.0001$ \\
\hline dept & 1 & 1 & -0.0151 & 0.5084 & 0.0008 & 0.8783 \\
\hline gen & 0 & 1 & -0.4885 & 0.2327 & 4.5884 & 0.0322 \\
\hline YearsAtCompany & & 1 & 0.5158 & 0.0575 & 80.4377 & $<.0001$ \\
\hline DistanceFromHome & & 1 & -0.0632 & 0.0138 & 20.8457 & $<.0001$ \\
\hline NumCompaniesWorked & & 1 & -0.1317 & 0.0463 & 8.0999 & 0.0044 \\
\hline Joblnvolvement & 1 & 1 & -2.1390 & 0.5742 & 13.8898 & 0.0002 \\
\hline Joblnvolvement & 2 & 1 & -1.0228 & 0.4878 & 4.7852 & 0.0287 \\
\hline Joblnvolvement & 3 & 1 & -0.5820 & 0.4452 & 1.5830 & 0.2088 \\
\hline JobLevel & 1 & 1 & -3.0557 & 1.1748 & 8.7839 & 0.0083 \\
\hline JobLevel & 2 & 1 & -1.1845 & 1.1791 & 1.0263 & 0.3110 \\
\hline JobLevel & 3 & 1 & -0.8542 & 1.2381 & 0.5858 & 0.4401 \\
\hline JobLevel & 4 & 1 & -0.2415 & 1.6000 & 0.0228 & 0.8800 \\
\hline JobSatisfaction & 1 & 1 & -1.8203 & 0.3387 & 28.2280 & $<.0001$ \\
\hline JobSatisfaction & 2 & 1 & -1.1278 & 0.3481 & 10.4971 & 0.0012 \\
\hline JobSatisfaction & 3 & 1 & -0.8905 & 0.3117 & 10.0971 & 0.0015 \\
\hline
\end{tabular}

Figure 2. Logistic regression output

Source: Authors' own research. 
The internal coding (Response Profile) assigns the smaller code to zero and the bigger to one. It is important to assign the codes according to the objectives of the study, as logistic regression estimates probability of an event occurring. Thus, the higher the value, the more likely the event. We want to estimate the probability that an employee will leave in less than 5 years (chosen to have as much attrition as possible over a reasonable period), so this event was assigned to 1 .

The Class Variable Information table indicates how the categorical predictors were coded. Generally, the last category is used as base for comparison. Taking department as an example, we have three levels: HR, R\&D and Sales. There are two codes: dept_ $0=1$ if employee works in HR, 0 otherwise, respectively dept_1=1 if employee works in R\&D, 0 otherwise. The Sales department will be used as base and has code 0 .

The Model fit statistics table contains several criteria for evaluating the model's goodness-of-fit. The lower the values in the table, the better the model. Without any predictors (Intercept only), the values are around 1000 for all three statistics, meaning the "prediction" consists of allocating all answers to the most frequent category. Including factors (Intercept and covariates), the values become almost half, thus estimation power is greatly improved.

Type 3 Analysis of Effects shows which of the predictors have an overall significant impact (if $(\mathrm{Pr}>\mathrm{Chi}$ _Sq) $<0.05)$ on the probability that an employee will leave. In this case, all have significant impact, but for further details we need to analyze Figure 3 (odds ratios). In the data, the code 0 for travelling represents those who are not required to travel, 1 is for rare travelling and 2 for frequent travelling. The odds ratios for those who never travel or travel rarely compared to those who travel frequently (travel_0_vs_2 and travel_1_vs_2) are greater than 1, which means these categories are more likely than the base category to leave. Thus, having this requirement in the job description may counter voluntary attrition. Those who never travel have higher odds of leaving the company even than those travelling rarely (travel_1_vs_2 $=3.045$, while travel_0_vs_2 $=5.922$ ). Given that most employees work in the R\&D department, this may suggest their dissatisfaction with not being able to attend conferences or other scientific events.

Model accuracy is assessed the help indicators derived from the confusion matrix (lower part of Figure 3). Percent Concordant/Discordant represent the percent of cases correctly/incorrectly classified. The right-side indicators show how well the model predicts the actual data. For example, the closer to 1 Sommers' $D$ is, the closer the predicted and actual values are.

Given a sufficiently large dataset, machine learning techniques can also be applied, as well as cross-validation and sample imbalance correction. The latter is useful because we only have 162 employees who left earlier than 5 years, compared to the remaining 1308 . Even by constantly assigning all cases to likely to stay category, the model would be right almost $90 \%$ of the time. This poses the risk od not dealing with the problem until it becomes big enough for the model to pick it up. On the other hand, cross-validation ensures the model does not overfit the training data and perform poorly afterwards. 


\begin{tabular}{|l|r|r|r|}
\hline \multicolumn{3}{|c|}{ Odds Ratio Estimates } \\
\hline Effect & Point Estimate & \multicolumn{2}{|c|}{ Confidence Limits } \\
\hline ovt 0 vs 1 & 7.023 & 4.400 & 11.208 \\
\hline marital 0 vs 2 & 0.288 & 0.155 & 0.536 \\
\hline marital 1 vs 2 & 0.956 & 0.510 & 1.794 \\
\hline travel 0 vs 2 & 5.922 & 2.230 & 15.725 \\
\hline travel 1 vs 2 & 3.045 & 1.791 & 5.177 \\
\hline dept 0 vs 2 & 3.314 & 1.962 & 5.598 \\
\hline dept 1 vs 2 & 0.985 & 0.364 & 2.688 \\
\hline gen 0 vs 1 & 0.607 & 0.385 & 0.959 \\
\hline YearsAtCompany & 1.675 & 1.497 & 1.875 \\
\hline DistanceFromHome & 0.939 & 0.914 & 0.985 \\
\hline NumCompaniesWorked & 0.877 & 0.801 & 0.980 \\
\hline Joblnvolvement 1 vs 4 & 0.118 & 0.038 & 0.383 \\
\hline Joblnvolvement 2 vs 4 & 0.360 & 0.144 & 0.899 \\
\hline Joblnvolvement 3 vs 4 & 0.570 & 0.238 & 1.364 \\
\hline JobLevel 1 vs 5 & 0.047 & 0.005 & 0.471 \\
\hline JobLevel 2 vs 5 & 0.303 & 0.030 & 3.054 \\
\hline JobLevel 3 vs 5 & 0.385 & 0.034 & 4.343 \\
\hline JobLevel 4 vs 5 & 0.785 & 0.034 & 18.074 \\
\hline JobSatisfaction 1 vs 4 & 0.162 & 0.084 & 0.313 \\
\hline JobSatisfaction 2 vs 4 & 0.324 & 0.164 & 0.640 \\
\hline JobSatisfaction 3 vs 4 & 0.371 & 0.202 & 0.684 \\
\hline
\end{tabular}

\begin{tabular}{|l|r|l|r|}
\hline \multicolumn{4}{|c|}{ Association of Predicted Probabilities and Observed Responses } \\
\hline Percent Concordant & 93.3 & Somers' D & 0.887 \\
\hline Percent Discordant & 6.7 & Gamma & 0.867 \\
\hline Percent Tied & 0.0 & Tau-a & 0.170 \\
\hline Pairs & 211896 & C & 0.833 \\
\hline
\end{tabular}

Figure 3. Logistic regression parameter estimations

Source: Authors' own research.

A general interpretation of our model is that the profile of the employee who is most likely to leave can be obtained by choosing the biggest significant odds ratios for each variable. Thus, these employees would be men, probably in the second half of their career and life (long tenure, married/divorced, living close to the office), who worked in few companies, currently feeling overwhelmed by work and might regard travelling as detachment from it for a short time. Similarly, we can derive the profile of the employees most likely to stay (Figure 5).

To take the analysis a step further, we can drop the 5-year condition by employing survival analysis. The output is similar to that of logistic regression (Figure 4), the essential difference being that in this case we interpret the hazard ratios. In other words, this model indicates what characteristics contribute most to employees "surviving" in the company for a longer period. 


\begin{tabular}{|c|c|c|c|c|c|}
\hline \multicolumn{6}{|c|}{ Class Level Information } \\
\hline \multirow{2}{*}{$\begin{array}{l}\text { Class } \\
\text { gen }\end{array}$} & \multirow{2}{*}{$\begin{array}{l}\text { Value } \\
0\end{array}$} & \multicolumn{4}{|c|}{ Design Variables } \\
\hline & & 1 & & & \\
\hline & 1 & 0 & & & \\
\hline \multirow[t]{2}{*}{ ovt } & 0 & 1 & & & \\
\hline & 1 & 0 & & & \\
\hline \multirow[t]{3}{*}{ marital } & 0 & 1 & 0 & & \\
\hline & 1 & 0 & 1 & & \\
\hline & 2 & 0 & 0 & & \\
\hline \multirow[t]{3}{*}{ travel } & 0 & 1 & 0 & & \\
\hline & 1 & 0 & 1 & & \\
\hline & 2 & 0 & 0 & & \\
\hline \multirow[t]{3}{*}{ dept } & 0 & 1 & 0 & & \\
\hline & 1 & 0 & 1 & & \\
\hline & 2 & 0 & 0 & & \\
\hline \multirow[t]{4}{*}{ Joblnvolvement } & 1 & 1 & 0 & 0 & \\
\hline & 2 & 0 & 1 & 0 & \\
\hline & 3 & 0 & 0 & 1 & \\
\hline & 4 & 0 & 0 & 0 & \\
\hline \multirow[t]{5}{*}{ JobLevel } & 1 & 1 & 0 & 0 & 0 \\
\hline & 2 & 0 & 1 & 0 & 0 \\
\hline & 3 & 0 & 0 & 1 & 0 \\
\hline & 4 & 0 & 0 & 0 & 1 \\
\hline & 5 & 0 & 0 & 0 & 0 \\
\hline \multirow[t]{4}{*}{ JobSatisfaction } & 1 & 1 & 0 & 0 & \\
\hline & 2 & 0 & 1 & 0 & \\
\hline & 3 & 0 & 0 & 1 & \\
\hline & 4 & 0 & 0 & 0 & \\
\hline
\end{tabular}

Summary of the Number of Event and Censored Values

\begin{tabular}{|r|r|r|r|}
\hline Total & Event & Censored & $\begin{array}{r}\text { Percent } \\
\text { Censored }\end{array}$ \\
\hline 1470 & 237 & 1233 & 83.88 \\
\hline
\end{tabular}

\begin{tabular}{|l|r|r|}
\hline \multicolumn{3}{|c|}{ Convergence Status } \\
\hline Convergence criterion (GCONV=1E-8) satisfied. \\
\begin{tabular}{|l|r|r|}
\hline \multicolumn{3}{|c|}{ Model Fit Statistics } \\
\hline Criterion & $\begin{array}{r}\text { Without } \\
\text { Covariates }\end{array}$ & $\begin{array}{r}\text { With } \\
\text { Covariates }\end{array}$ \\
\hline-2 LOG L & 3153.989 & 2728.822 \\
\hline AIC & 3153.989 & 2788.822 \\
\hline SBC & 3153.989 & 2838.183 \\
\hline
\end{tabular}
\end{tabular}

\begin{tabular}{|l|r|r|r|}
\hline \multicolumn{4}{|c|}{ Testing Global Null Hypothesis: BETA=0 } \\
\hline Test & Chi-Square & DF & Pr $>$ ChiSq \\
\hline Likelihood Ratio & 425.1674 & 20 & $<.0001$ \\
\hline Score & 434.7911 & 20 & $<.0001$ \\
\hline Wald & 374.0339 & 20 & $<.0001$ \\
\hline
\end{tabular}

Note: No (additional) effects met the 0.05 level for removal from the model.

\begin{tabular}{|l|r|r|r|}
\hline \multicolumn{4}{|c|}{ Type 3 Tests } \\
\hline Effect & DF & Wald Chi-Square & Pr $>$ ChiSq \\
\hline ovt & 1 & 70.5741 & $<.0001$ \\
\hline marital & 2 & 35.3244 & $<.0001$ \\
\hline travel & 2 & 17.4724 & 0.0002 \\
\hline dept & 2 & 56.1138 & $<.0001$ \\
\hline gen & 1 & 7.2007 & 0.0073 \\
\hline DistanceFromHome & 1 & 15.5913 & $<.0001$ \\
\hline NumCompaniesWorked & 1 & 41.2574 & $<.0001$ \\
\hline Joblnvolvement & 3 & 22.8594 & $<.0001$ \\
\hline JobLevel & 4 & 172.8151 & $<.0001$ \\
\hline JobSatisfaction & 3 & 12.5679 & 0.0057 \\
\hline
\end{tabular}

\begin{tabular}{|c|c|c|c|c|c|c|c|c|}
\hline \multicolumn{9}{|c|}{ Analysis of Maximum Likelihood Estimates } \\
\hline Parameter & & DF & $\begin{array}{l}\text { Parameter } \\
\text { Estimate }\end{array}$ & $\begin{array}{r}\text { Standard } \\
\text { Error }\end{array}$ & Chi-Square & $\mathrm{Pr}>\mathrm{ChiSq}$ & $\begin{array}{r}\text { Hazard } \\
\text { Ratio }\end{array}$ & Label \\
\hline ovt & 0 & 1 & -1.12320 & 0.13370 & 70.5741 & $<.0001$ & 0.325 & ovt 0 \\
\hline marital & 0 & 1 & 0.85096 & 0.20111 & 22.3582 & $<.0001$ & 2.588 & marital 0 \\
\hline marital & 1 & 1 & 0.22441 & 0.20855 & 1.1579 & 0.2819 & 1.252 & marital 1 \\
\hline travel & 0 & 1 & -1.13882 & 0.32229 & 12.4859 & 0.0004 & 0.320 & travel 0 \\
\hline travel & 1 & 1 & -0.49254 & 0.14980 & 10.7988 & 0.0010 & 0.611 & travel 1 \\
\hline dept & 0 & 1 & -1.13319 & 0.15199 & 55.5858 & $<.0001$ & 0.322 & dept 0 \\
\hline dept & 1 & 1 & -0.49691 & 0.31890 & 2.4280 & 0.1192 & 0.608 & dept 1 \\
\hline gen & 0 & 1 & 0.37339 & 0.13915 & 7.2007 & 0.0073 & 1.453 & $g e n 0$ \\
\hline DistanceFromHome & & 1 & 0.03053 & 0.00773 & 15.5913 & $<.0001$ & 1.031 & \\
\hline NumCompaniesWorked & & 1 & 0.15784 & 0.02459 & 41.2574 & $<.0001$ & 1.171 & \\
\hline Joblnvolvement & 1 & 1 & 1.27255 & 0.34268 & 13.7904 & 0.0002 & 3.570 & Joblnvolvement 1 \\
\hline Joblnvolvement & 2 & 1 & 0.81510 & 0.30876 & 6.9692 & 0.0083 & 2.259 & Joblnvolvement 2 \\
\hline Joblnvolvement & 3 & 1 & 0.43217 & 0.29719 & 2.1147 & 0.1459 & 1.541 & Joblnvolvement 3 \\
\hline JobLevel & 1 & 1 & 3.77275 & 0.59225 & 40.5798 & $<.0001$ & 43.500 & Joblevel 1 \\
\hline JobLevel & 2 & 1 & 1.86534 & 0.59448 & 9.8456 & 0.0017 & 6.458 & Joblevel 2 \\
\hline Joblevel & 3 & 1 & 1.83047 & 0.59123 & 9.5854 & 0.0020 & 6.237 & Joblevel 3 \\
\hline Joblevel & 4 & 1 & -0.31818 & 0.65105 & 0.2389 & 0.6250 & 0.727 & Joblevel 4 \\
\hline JobSatisfaction & 1 & 1 & 0.64833 & 0.19164 & 11.4455 & 0.0007 & 1.912 & JobSatisfaction 1 \\
\hline JobSatisfaction & 2 & 1 & 0.44640 & 0.20961 & 4.5353 & 0.0332 & 1.563 & JobSatisfaction 2 \\
\hline JobSatisfaction & 3 & 1 & 0.52125 & 0.18654 & 7.8083 & 0.0052 & 1.684 & JobSatisfaction 3 \\
\hline
\end{tabular}

Figure 4. Survival analysis (Cox proportional hazards) output

Source: Authors' own research. 
As before, the basic output internal coding of the outcome independent categorical variables, information regarding model goodness-of-fit and parameter estimates (Figure 4). Since some data is interpreted the same as for logistic regression, we will focus only on the tables that differ. Firstly, we have Summary of the Number of Event and Censored Values, where we see that the model, despite predicting a binary outcome (event/censored), takes all events into consideration, regardless of the period before leaving. Secondly, the impact of the predictors included in the model is assessed globally, not individually as in logistic regression (Testing Null Hypothesis: $B E T A=0$ ), and all statistics indicate that the parameters introduced have a significant impact (because (Pr $>$ Chi_sq) $<0.05)$.

Finally, the parameter estimates table (bottom) contains the hazard ratios instead of the odds ratios, thus indicating how much more likely is the category analyzed to "survive" over the entire time, compared to the base category. The more likely a certain category is to not leave, the more important the factor in employee retention on the long term.

The conclusions are similar to those obtained from logistic regression, because the median number of years spent in the company is 5. For illustration purposes, we also estimated the logistic regression for likelihood of leaving before 1-year and 10-year periods. The results are presented comparatively in Figure 5 below. As the period of interest shortens, the logistic model detects fewer important predictors and the problem is that an HR specialist is likely more interested in the short-term attrition rates.

\begin{tabular}{lcrrr}
\hline \multicolumn{1}{c}{ Variable } & $\begin{array}{c}\text { Logistic model } \\
\text { (1-year profile) }\end{array}$ & $\begin{array}{c}\text { Logistic model } \\
\text { (5-years profile) }\end{array}$ & $\begin{array}{c}\text { Logistic model } \\
\text { (10-years profile) }\end{array}$ & $\begin{array}{c}\text { Cox model } \\
\text { (profile) }\end{array}$ \\
\hline Overtime & No & No & No & No \\
Marital & Single & Single & Single & Single \\
Travel & Frequently & Frequently & Frequently & Frequently \\
Department & Non-sign. & Sales/HR & Sales/HR & Sales \\
\hline Gender & Non-sign. & Female & Female & Female \\
\hline DistFromHome & Further & Further & Further & Further \\
NumCompWorked & Non-sign. & More & More & More \\
\hline JobInvolvement & Non-sign. & 1 & 1 & 1 \\
JobLevel & Non-sign. & 1 & 1 & 1 \\
JobSatisfaction & 1 & 1 & 1 & 1 \\
YearsAtCompany & Much fewer & Fewer & Fewer & N/A \\
„ & & & &
\end{tabular}

Figure 5. Profile of least likely to leave employee

Source: Authors' own research.

Besides the methods presented, which are merely scratching the surface of analytics, there is a myriad of other techniques that can be used to obtain even greater insight. However, the information presented in the predictive section is not nearly as accessible to HR specialists and it requires them to collaborate with analysts to extract actionable insight from the data. Also, it relies on large datasets and requires important computing resources. On the other hand, the information is much more detailed and can be used for acting towards preventing attrition, requiring less face-to-face interaction. For a very big company, within which qualitative approach is not feasible, such analyses proved more time and resource efficient than traditional ones. 


\section{Conclusion}

The present paper aimed at presenting several options an HR specialist can employ to analyze voluntary attrition. The paper focuses on methods, generation of output and extraction of insight, rather than providing directions of action.

As increasingly more Millennials enter the labor market, a paradigm shift is necessary in order to attract and retain employees, as the younger generations have different sets of values. For identifying directions of action, several methods can be employed.

We started by looking into descriptive methods (turnover and retention rates, and cohort analysis, respectively), which present several important advantages, such as easiness to compute and data availability. Combined with qualitative research in the form of interviews or focus-groups, they prove very efficient for smaller companies where, on the one hand, direct contact with the employees is possible and desirable, and, on the other hand, often do not dispose of the infrastructure required for analytics.

Next, we peeked at logistic regression and survival analysis as predictive methods. They allow for more in depth exploration, sketching a profile of employees most likely to leave/stay, and highlighting possible causes for voluntary attrition. This paves the way towards mitigation and event prevention. However, the advantages can be surpassed by the downside of resource intensiveness that characterizes them. On top of requiring large amounts of data, they also incur costs with data storage and processing power. Employing at least one analyst to do the data processing and communicate results to HR/business is also a must. Therefore, such an approach is mostly feasible for large companies, where direct interaction between HR and all employees is not possible, and who can usually afford the infrastructure.

HR Analytics research is only at the beginning so further research into various other analysis methods is open and welcomed. While business is ahead of academics on this matter, already testing empirically several approaches, a uniform and theoretical approach can benefit all stakeholders. Possible topics might include, for example, unsupervised machine learning and it's use in studying voluntary employment attrition and human behavior in general.

A final remark: despite the glamour of analytics and its unquestionable contribution to business and research, the best methods to employ are the ones that give the biggest return on investment. The most appropriate methods to use are the ones that solve the problem, not the ones that everybody else uses.

\section{References}

Andert, D. (2011). Alternating Leadership as a Proactive Organizational Intervention: Addressing the Needs of the Baby Boomers, Generation Xers and Millennials. Journal of Leadership, Accountability and Ethics, 8(4), 67-83.

Angrave, D., Charlwood, A., Kirkpatrick, I., Lawrence, M., \& Stuart, M. (2016). HR and Analytics: why HR is set to fail the big data challenge. Human Resource Management Journal, 26(1), 1-11.

Aral, S., Brynjolfsson, E., \& Wu, L. (2012). Three-way complementarities: Perfomance pay, human resource analytics, and information technology. Management Science, 58, 913931.

Bassi, I. (2011). Raging debates in HR Analytics. People \& Strategy, 34, 14-18.

Cahill, T. F., \& Sedrak, M. (2012). Leading a Multigenerational Workforce: Strategies for Attracting and Retaining Millennials. Frontiers of Health Services Management, 29(1), 
3-15.

Deal, J., Altman, D., \& Rogelberg, S. (2010). Millennials at work: what we know and what we need to do (if anything). Journal of Business \& Psychology, 25(2), 191-199.

Hosmer, D. W., \& Lemeshow, S. (2000). Applied Logistic Regression (2nd ed.). New York: Wiley.

Hosmer, D. W., Lemeshow, S., \& May, S. (2008). Applied Survival Analysis: Regression Modeling of Timeto- Event Data (2nd ed.). New York: Wiley.

Lawler III, E. E., Levenson, A., \& Boudreau, J. W. (2004). HR metrics and analytics: Use and Impact. Human Resource Planning, 27, 27-35.

Levenson, A. (2010). Millennials and the world of work: an economist's perspective. Journal of Business \& Psychology, 25(2), 257-264.

McQuerrey, L. (2019, March 6). Employee Turnover Vs. Attrition. Retrieved from Chron: https://smallbusiness.chron.com/employee-turnover-vs-attrition-15846.html

Meyers, K., \& Sadaghiani, K. (2010). Millennials in the workplace: a communication perspective on millennials' organizational relationships and performance. Journal of Business \& Psychology, 25(2), 225-238.

Mondare, S., \& Carson, M. (2011). Maximizing the impact and effectiveness of HR Analytics to drive business outcomes. People \& Strategy, 34, 20-27.

Rasmussen, T., \& Ulrich, D. (2015). Learning from practice: how HR analytics avoids being a management fad. Organizational Dynamics, 44, 236-242.

Smith, T. J., \& Nichols, T. (2015). Understanding the Millennian Generation. Journal of Business Diversity, 15(1), 39-47.

Smola, K. W., \& Sutton, C. D. (2002). Generational differences: Revisiting generational work values for the new millennium. Journal of Organizational Behavior, 23(4), 363-382. 